\title{
Elevada prevalencia de marcadores de Hepatitis B y Delta en el valle interandino de Abancay.
}

High prevalence of hepatitis $B$ and Delta markers in the interandean valley of Abancay.

INDACOCHEA Sonia ${ }^{1}$, GOTUZZO Eduardo ${ }^{2}$, DE LA FUENTE Justo ${ }^{1}$, PHILLIPS Irving ${ }^{3}$ y WHIGNAL Stephen ${ }^{3}$

${ }^{1}$ Centro Médico Santa Teresa de Abancay, Apartado 22.

${ }^{2}$ Instituto de Medicina Tropical" Alexander von Humboldt". Universidad Peruana Cayetano Heredia.

${ }^{3}$ NAMRID, Lima, Perú.

\section{SUMMARY}

214 helthy persons were studied prospectively in the city of Abancay, searching for hepatitis B and delta serological markers. HBs Ag was detected more frecuently in males than females $(16.2 \%$ vs $4.3 \%) ; 8$ of the $21 \mathrm{HbsAg}$ positive were younger than 10 years of age; $53.25 \%$ of the population had some marker of infection posite ( HbsAg $9.8 \%$, antiHBs $43.45 \%$ ). There was no significative difeference in relation to the well-known risk factors. There was some tendency to find the HbsAg posite in relation to the time of residence in Abancay. 9\% of the persons had hepatitis delta markers, being in children $18.7 \%$, and $5.2 \%$ in older of 30 years. The mayority of of these children never went out Abancay, meaning that the intefection was in the city. The past history of jaudice and jaudice among the relativs correlated significantly with hepatitis delta markers and not with hepatitis B markers.

KEY WORDS: Viral hepatitis, hepatitis B, Delta hepatitis.

\section{RESUMEN}

Se estudian de forma prospectiva, 214 personas supuestamente sanas de la ciudad de Abancay en búsqueda de marcadores de hepatitis B (HbsAg y anti-HbsAg) así como de Hepatitis Delta. Se detectó una significativa positividad de HbsAg en varones $16.2 \%$ $(16 / 99)$ en relación a mujeres $4.3 \%(5 / 115)$. Hubo una tendencia no significativa a ser más positiva la población pediátrica, 8 de 21 personas HbsAg positivo eran de 10 años. El 53.25\% de las personas estudiadas tenían algún marcador de infección (HbsAg 9.8\%, y Anti-HbsAg 43.45\%). No hubo diferencia significativa en factores de riesgo reconocidos (uso de inyectables, cirugía dental, etc.). Hubo una tendencia a ser más positivo el HbsAg en relación al tiempo de permanencia en Abancay. El 9\% (10/111) de las personas estudiadas tenían marcadores de Hepatitis Delta, siendo elevado en los niños $(18 / 7 \%)$ en relación a personas mayores de 30 años $(5.2 \%)$. La mayoría de estos 
niños nunca habían salido de Abancay lo que señala infección dentro de la ciudad. El antecedente personal de ictericia en el pasado y el antecedente de ictericia en la familia correlacionó significativamente con la presencia de Hepatitis Delta $(\mathrm{p}=0.05)$ y no con los marcadores de Hepatitis B.

PALABRAS CLAVE: Hepatitis viral, hepatitis B, hepatitis delta.

\section{INTRODUCCION}

Es reconocida la gran importancia epidemiológica en América Latina de la hepatitis viral, especialmente la hepatitis B(2) (17). Existe una alta tasa de portadores de HbsAg (antígeno de superficie), especialmente en área tropicales (17). Esta situación produce elevada mortalidad y morbilidad por hepatitis aguda o por sus secuelas a largo plazo (3). En el Perú, hay área con tasas de portadores HbsAg entre $0.8-3.5 \%$ en población general (17). Existen áreas de mayor endemicidad como Loreto y Abancay (18).

Desde que Rizetto descubriera el agente Delta en 1977, este agente RNA-viral ha tomado una notable importancia pues, sólo se replica en pacientes con infección aguda crónica de hepatitis $\mathrm{B}$; es altamente infectivo, se disemina rápidamente en las familias o en la comunidad infectada por virus B (16) con alta mortalidad. Es conocida la alta endemicidad de la región amazónica (17), así Hadler y colaboradores (8) mostraron la elevada frecuencia de agente Delta en brotes de hepatitis severa en indios de la Amazonía de Colombia y Venezuela.

Abancay, capital del Departamento de Apurímac (Perú), situada en un valle interandino a 2,395 metros s.n.m es una conocida área endémica de hepatitis desde hace más de 100 años, Bush en 1941 (19), Encinas en 1956(5), Gastelumendi en 1960(7), señalaron una frecuencia elevada de hepatitis con mortalidad importante. Méndez y colaboradores, estudiaron 2 brotes epidémica en Abancay (1976 y 1981), encontrando un alto porcentaje de portadores $(27.7$ y $33.3 \%$ ) entre los que habían padecidos hepatitis (más de $6 \mathrm{~m}$. y menos de $6 \mathrm{~m}$. respectivamente) y mayor porcentaje de portadores en menores de 15 años. También en 1984, Méndez detectó 3.8\% de seropositividad en 621 adultos de pobalción general de Abancay (18), lo que coloca a Abancay como área de gran endencimidad para hepatitis B.

El virus Delta es capaz de producir infecciones hepáticas agudas junto con el virus B (confección ), pudiendo ser causa del 6 al 30\% de las hepatitis fulminantes asociadas al virus B (14); así como infectar a portadores crónicos de antígeno de superficie (superinfección) siendo responsable, en este caso, del 2 al $20 \%$ de las hepatitis fulminantes (14). La infección por virus Delta tiene también la característica de agravar la enfermedad hepática crónica asociada a portadores de antígeno Australia (16); así aquellos que además de ser portadores tengan anticuerpo anti Delta tienen 4 veces más riesgo de enfermedad hepática crónica que aquellos que no tengan anticuerpos (1). Teniendo en cuenta el elevado porcentaje de portadores HbsAg y los ocasionales brotes epidémicos de hepatitis con mortalidad importante en Abancay, se evaluó la prevalencia de marcadores de hepatitis B y Delta en la población supuestamente sana de esa zona endémica.

\section{MATERIALES Y METODOS}


Se recolectaron muestras de sueros de 214 personas, aparentemente sanas, de distintos grupos que viven en la ciudad de Abancay, seleccionados sólo por facilidad de colaboración: personas que acudían a la consulta del Centro Médico Santa Teresa por causas no relacionadas a hepatitis $(\mathrm{N}=79)$; niños y niñas de dos colegios $(\mathrm{N}=48)$; niños del orfanato de Abancay, lugar donde en 1982 han ocurrido brotes de hepatitis $(\mathrm{N}=10)$; ancianos del asilo de Abancay (24=24); jóvenes varones sanos del Cuerpo de Bomberos de Abancay $(\mathrm{N}=31)$ y religiosas de Clausura $(\mathrm{N}=22)$. A todos os adultos, se les solicitó permiso voluntario para ingresar al proyecto. En el caso de los niños se solicitó a los padres o tutores la autorización para la participación de la evaluación.

A cada persona incluida en este estudio se le realizó lo siguiente: A) Entrevista epidemiológica llenando una ficha donde se consignaba edad, sexo, ocupación, estado civil de nacimiento y de procedencia, antecedentes importantes como: inyectables (más de 10 en su vida), transfusiones de sangre o derivados, visitas frecuentes al dentista (más de 10 veces en su vida). Drogadicción, homosexualidad, picaduras de mosquitos, viajes a la selva, hepatitis previa, antecedente familiar de hepatitis; B) extracción de 5cc. De sangre para dosaje de antígeno Australia, anti-antígeno Australia y anti Delta, según la técnica de ELISA descrita por los laboratorios ABBOT.

\section{RESULTADOS}

Fueron enroladas 214 personas, 114 mujeres y 90 hombres. En 21 (9.8\%) detectamos HbsAg y en 93(43.4\%) anti HbsAg, que señalan una tasa de marcadores de infección del orden de 53.2\%. De los 21 portadores, 20 eran menores de 30 años. La prevalencia de portador crónico fue significativamente mayor en varones $(16.2 \%)$ que en mujeres $(4.3 \%)(\mathrm{p}<0-01)$. El lugar de nacimiento no fue un factor significativo de riesgo, aunque las personas que nacieron fuera de la ciudad de Abancay o del departamento de Apurímac, tuvieron una tendencia a ser menos positivos (Tabla1).

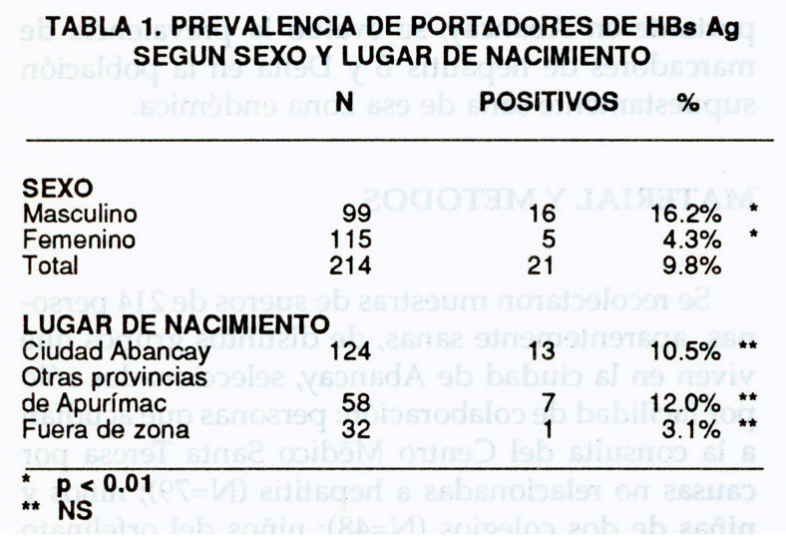

En la búsqueda de los factores de riego tradicionales, fueron excluidos 22 pacientes por datos incompletos o información no confiable. En la otras 192 personas, no encontramos diferencias estadística entre los positivos y negativos, en relación al uso de inyectables, visitas a odontólogos, antecedente de picaduras de mosquito e ictericia previa (Tabla 2). 


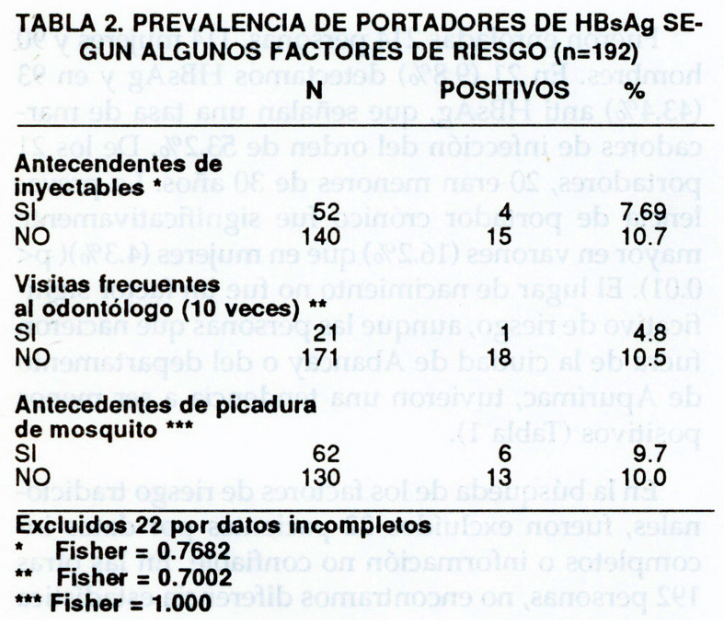

El tiempo de permanencia en Abancay, no mostró diferencia estadística, pues los límites de confianza son grandes con el pequeño tamaño de la muestra. Se nota, sin embargo, una tendencia a tener una mayor positividad luego de los 5 años (TABLA 3).

TABLA 3. PREVALENCIA DE HBsAg SEGUN TIEMPO DE
PERMANENCIA EN ABANCAY (n=194)

\section{Se excluyeron los 10 casos del orfelinato y 10 con} información incompleta.

La presencia de anticuerpo anti delta, se evaluó en las últimas 111 personas; 10 fueron positivos $(9 \%)$ y todos tenían algún marcador de infección por virus B. De ellos 9 fueron varones y sólo 1 fue mujer. Un hallazgo adicional, es la mayor frecuencia encontrada en población infantil y adultos jóvenes. Adicionalmente, detectamos que 4 de los 10 casos nunca habían salido de la ciudad de Abancay (Tabla 4).

\begin{tabular}{|c|c|c|c|}
\hline \multirow[b]{2}{*}{ EDAD } & \multicolumn{2}{|c|}{$\begin{array}{l}\text { EVALENCIA DE ABs A } \\
\text { SEGUN LA EDAD } \\
\text { ( } n=111 \text { personas) }\end{array}$} & \multirow[b]{2}{*}{$\%$} \\
\hline & CASOS & POSITIVOS & \\
\hline \multirow[t]{2}{*}{$\begin{array}{l}0-9 \\
10-19 \\
20-29 \\
30\end{array}$} & $\begin{array}{l}16 \\
48 \\
28 \\
19\end{array}$ & $\begin{array}{l}3 \\
4 \\
2 \\
1\end{array}$ & $\begin{array}{r}18.75 \\
8.3 \\
7.1 \\
5.2\end{array}$ \\
\hline & 111 & 10 & 9.0 \\
\hline
\end{tabular}

Se pudo evaluar el antecedente de ictericia en la historia personal y familiar en 192 personas y en 102 de las 111 en quienes se hicieron anticuerpos anti-Delta. La historia de ictericia, señaló una significativa positividad de anti-Delta (30.7\%) en comparación con aquellos que no la habían tenido $(5.7 \%)(\mathrm{p}<0-05 \%)$.En relación a la presencia del HbsAg, fue positivo en $19.4 \%$ de aquellos con historia de ictericia, en comparación con el $8.1 \%$ de aquellos sin historia de ictericia (n.s.). La familiar de ictericia tampoco 
mostró significancia para marcadores de HbsAg, sin embargo, los marcadores de antiDelta fueron más positivos cuando hubo ictericia en los familiares. $12.9 \%$, en relación a sólo 4.2\% cuando no hubo este dato epidemiológico (p 0 0.05) (Tabla 5).

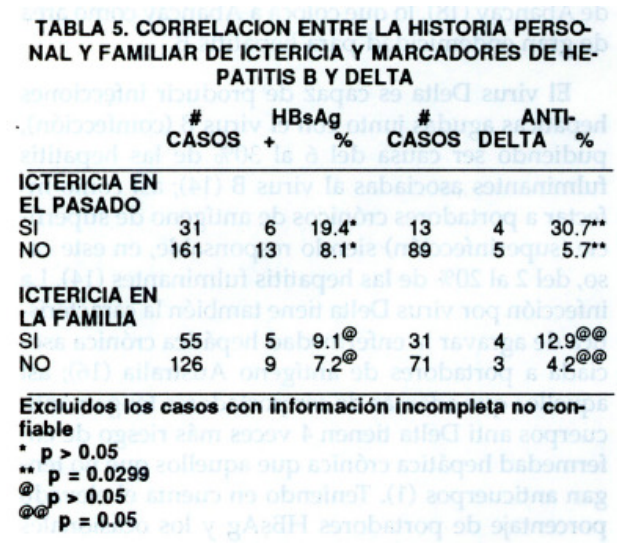

\section{DISCUSION}

La frecuencia de portadores "sanos" de antígeno de superficie en una población es un índice de la endemicidad de la hepatitis B en ella, considerándose alta endemicidad cuando el porcentaje varía entre 8 y $20 \%$ (3), siendo este demostrativo de la alta endemicidad en Abancay ya que encontramos positividad en el $9.8 \%$ de la población aparentemente sana.

En un estudio publicado por la OPS en 1985 se calcula que el porcentaje de portadores de HBsAg en el Perú entre 0.8-3.5\%, calculándose en 235,500 los portadores crónicos, destacándose la alta prevalencia en la zona amazónica (29. Garrido y Morales en 1973 hicieron $n$ estudio en población aparentemente sana de 3 regiones de Perú (6): Lima, Cerro de Pasco e Iquitos encontrando el 0,0 y 3\% de portadores, respectivamente. Madalengoitia y col. En 1975(11) encontraron que en oriente peruano el 1.8\% eran positivos al antígeno Australia. Por su parte, Méndez y colaboradores en 1983 estudiando la población de Iquitos encontraron al 2.5\% de portadores, con cifras mayores, con cifras mayores en otros lugares de la Selva Peruana como Requena $7.4 \%$. Todos estos estudios resulta la importancia de la endemia de hepatitis B en zonas de la Selva, llamando la atención que Abancay, zona andina, tuviera cifras tan altas de portadores crónicas del virus.

La edad a la que se contrae la infección por el virus de la hepatitis B es uno de los factores más importantes para la conversión al estado de portador crónico, así entre los adultos el 5 al $10 \%$ de infectados se convierten en portadores, mientras que en los lactantes cerca del $802 \%$ pasa al estado de portador luego de infección (3); así mismo el estado portador tiende a desaparecer con la edad, disminuyendo los títulos de antígeno de superficie (3) ambos hechos se han comprobado en el presente estudio, en el cual la mayor frecuencia de portadores está en las edades tempranas de la vida, disminuyendo progresivamente de tal modo que ningún portador tiene más de 50 años, demostrándose también que la mayor frecuencia del estado de portador es en varones $(3,12)$.

El hecho de que en Abancay no se presenten los conocidos factores de riesgo para adquirir la hepatitis B, tales como frecuentes visitas al dentista transfusiones sanguíneas, 
homosexuales, drogadicción, etc. Como se demuestra en este estudio, abre la posibilidad de considerar otras vías de transmisión, como la perinatal, que en algunos lugares tales como en ciudades de Asia $(3,15)$ y algunas zonas de América del Sur (2) explica la alta frecuencia de portadores de antígeno Australia y la transmisión por picadura de vectores, postulada por algunos autores $(4,6,3)$ y también sugerida por Rolando y colaboradores en 1983 en Abancay (12)

La infección por virus Delta que aunque de distribución mundial tiene ciertas variaciones geográficas (13), dando lugar a dos patrones epidemiológico distintos (16): Uno endémico asociado a difusión no parenteral del virus, como en el sur de Italia, el área Amazónica y algunos partes de África; se postula en este caso la transmisión por contacto de personas a persona a, en ausencia de exposición percútanea (9). El otro, esporádico, asociado a transmisión parenteral, como el caso de hemofílicos, politransfundidos y drogadictos y drogadictos parenterales, como sucede en Norteamérica y en el Oeste de de Europa (16).

Abancay, área de alta prevalencia de portadores de antígeno de superficie, lo es también de infección Delta, lo que se ha evidenciado a través de este trabajo y que asumimos podría corresponder al patrón endémico y posiblemente en algunos casos al epidémico. Hay reporte en la literatura de superinfección por virus Delta, entre los indios Yucpas de Venezuela entre los años 1979 y 1981(8), en los cuales había una alta prevalencia de portadores crónicos de antígeno de superficie. Esta superinfección afectó a 149 indio en 3 años, alcanzado dimensiones de epidemia en la que 34 de ellos fallecieron. Está también el reporte de la epidemia ocurrida en "Sierra Nevada de Santa Marta" en Colombia entre los años 1978 y 1981(10), en que se encontró que el 60\% de portadores de antígeno Australia tenían anti-Delta positivo; ambos reportes sugieren que una infección Delta es capaz de producir brotes epidémicos en una población en la que anteriormente habían una alta proporción de portadores, explicados posiblemente por superinfección (8). El hallazgo del $9 \%$ de personas con anti-Delta positivo, indica una considerable prevalencia de infección Delta en Abancay, y el hallazgo de una aparente mayor frecuencia en los niños indicaría que esta infección ocurre en etapas temprana de la vida.

\section{Agradecimientos: Personal Paramédico del Centro M130dico Santa Teresa de Abancay (Sr. Marcelino Carvajal y otros)}

\section{BIBLIOGRAFIA}

1.Arico S. Clínicas significance of antibody to the hepatitis delta virus in symptomless HBs Ag carriers. Lancet 1985,:356-358

2.Boletín Epidemiológico - Organización Panamericana de la Salud. La Hepatitis en las Américas. 1985,6:1-7.

3.Boletín Epidemiológico - Organización Panamericana de la Salud. Hepatitis B y Hepatitis Delta 1984, 5:1-8

4.Dick S, Tamburro CH. Leevy, CM. Hepatitis B antigen in urban-caught mosquitoes. JAMA 1974,229:1627-1629.

5.Encinas E, Palacios O, Campos C, y col. Contribución a la clínica y anatomía de la hepatitis epidémica aguda en Abancay. Ann de la Fac de Med. 1956, XXXIX:1-72.

6.Garrido G, Morales V. Antígeno australiano asociado a la hepatitis en el Perú. Acta Med. Per. 1973, 2:107-112. 
7.Gatelumendi R, Burstein M, León Barúa R. Contribuición al estudio de la hepatitis viral endemo-epidémica en Abancay. Ann. De la Fac. de Med. 1960, XLIII:629-6650.

8.Hadler S, Monzón M, Ponceño A. et al. Delta virus infection and severe Hepatitis. Ann Int Med. 1984,100:339-344.

9.Jacobson IM. Epidemiology and clinical impact of D virus (Delta) infection. Hepatology 1985, 5:188-191.

10.Ljunggren KE, Patorroyo ME, Engle R, et al. Viral hepatitis in Colombia: A study of the hepatitis of the Sierra Nevada de Santa Marta. Hepatology 1985, 5:299-304.

11. Madalengoitia J, Ishida N, Unemay T. et al. Prevalencia del antígeno de la hepatitis B en residentes y casos de hepatitis en el Perú. Bol Sanit Panam 1975,78:445-451.

12.Roalndo N, Figueroa R, Takano J, Guillén C, Lizárraga J. y Have J. Estudio clínico, bioquímico y anatomopatológico de los portadores de antígeno de su superficie de la hepatitis B en Abancay. Diagnóstico 1983, 12:5-17.

13.Sarver DK. Hepatitis un clínicas practice : Non A non B and delta Hepatitis. Postgrad Med 1986, 79 :221-230

14. Smedile A, Farci P, Verme G. Influence of delta infection on severity of Hepatitis B. Lancet 1982,2:945-947.

15.Tanaka T, Nagal M, Yshihara S. Changing pattern of age specific prevalence of hepatitis B, sufrace antigen and corresponding antibody in Japan. Am J Epidemiol 1986.124:368-371.

16.Vildosola H. Hepatitis delta. Rev. Gastroent del Perú 1985,5:191-198.

17.Hadler S, Fay O, Pinheiro F. y col. La Hepatitis en las Américas: Informe del Grupo Colaborador de OPS. Bol. Sanit Panam 1987,103:185-209.

18. Méndez M, Kruger H, Sánchez S. Prevalencia de marcadores serológicos de Hepatitis Vírica en diversos grupos de población del Perú. Bol Sanit Panam 1989, 106:127-138.

19.Bush C. Ictecia epidémica. Reforma Médica de Lima 194, 26:788-791. 